\title{
Indirect bonding: A literature review
}

\author{
Sertaç Aksakalli, Abdullah Demir \\ Department of Orthodontics, Selcuk University School of Dentistry, Konya, Turkey
}

\author{
Address for correspondence: \\ Dr. Sertaç Aksakalli, \\ Department of Orthodontics, \\ Selcuk University School of Dentistry, \\ Selçuklu-42075, Kampüs/Konya, Turkey. \\ E-mail:sertacaksakal@gmail.com
}

\begin{abstract}
With the increased interest in recently years, indirect bonding became more popular. This technique enhances clinician's ability to communicate with patients and parents more and enhances chair-time savings. There are many kinds of indirect bonding and new techniques were presented to literature recently. There are so many steps and applications in indirect bonding. So all these are opened to modification and also modified too. With any new development, there will be some trepidation. There is always a natural fear of unknown. In indirect bonding, there were doubts about bond failures but studies revealed that there is no significant difference between direct and indirect technique on bond strength.
\end{abstract}

Key words

Adhesive, bond, indirect bonding, tray

\section{INTRODUCTION}

Indirect bonding is a technique, in which orthodontic brackets and other attachments are transferred from dental casts (working models) and bonded onto dentition using a transfer device. ${ }^{[1]}$ Indirect bonding was first described in detail by Silverman and Cohen in 1972 and at first trials, they used cements for bonding brackets onto working models, also prepared a thermoplastic transfer tray. In following years, they developed this technique by using different resins (methymetacrylate, Nuva-Fil bis-GMA etc.), and in 1975, they prolonged chairtime by using light cured adhesive. ${ }^{[2,3]}$ At the beginning of 1980s, thermally cured adhesives were started to use. The working models with brackets attached were heated to $250-300{ }^{\circ} \mathrm{F}$ for approximately 15 to 20 minutes as a means of curing the resin. But, in this procedure, brackets were drifting from ideal places and these high temperatures were not appropriate for some materials such as non-ceramic esthetic brackets. ${ }^{[4]}$ In 1990s, Hamula who worked on light cured adhesives, reported the advantages of this kind of adhesives. ${ }^{[5]}$ In 2002, FiltekFlow ${ }^{\circledR}(3 \mathrm{M}$ ESPE, St.Paul, MN), a flowable composite developed for use in tunnel preperations, class

\begin{tabular}{|l|l|}
\hline \multicolumn{2}{|c|}{ Access this article online } \\
\hline Quick Response Code: & Website: \\
\hline & www.ejgd.org \\
\cline { 2 - 3 } & \\
\hline
\end{tabular}

IV cavities and fissure sealant, was incorporated into indirect bonding by Miles. Thus, this material reduced void risks under bracket base, and good handling of composite was achieved. ${ }^{[6]}$

\section{THE ADVANTAGES OF INDIRECT BONDING}

Indirect bonding enhances clinician's ability to communicate with patients and parents at the initial phases. Besides, it enhances chair-time savings so exhausts either clinician or patient less, simplifies archwire changes, and gives less stress. ${ }^{[7,8]}$

There have been few studies done, that compare direct versus indirect bonding in relationship to accuracy. Hodge and colleagues conducted a clinical trial comparing the accuracy of two bonding systems and concluded, "There was no significant difference between the mean errors produced by the two methods of bracket placement." Koo and colleagues had the similar results in their own study. ${ }^{[9,10]}$ When optimum accuracy gained, inappropriate occlusal contacts eliminates. Therefore, risks about TMJ disorders, root resorption, and elongation of treatment can decrease. ${ }^{[1-13]}$

About bond strengths, Hocevar and Vincent reported similar results between two techniques in an in-vitro study with extracted human premolars. Milne and colleagues found no difference also. ${ }^{[10,14]}$

Another advantages of indirect bonding also includes significant cost savings, elimination of the need for 
separators and bands, easier ability for rebonding, better in-out-vertical controls, better overcorrections, and optimal use of staff. ${ }^{[9]}$

\section{THE DISADVANTAGES OF INDIRECT BONDING}

Indirect bonding needs more laboratory time and educated staffs for laboratory steps such as bracket placement or preparation of transfer trays. Most of the resins used in market designed for direct bonding; therefore, there is almost no appropriate resins directly designed for indirect bonding. ${ }^{[15]}$

The bonding procedure happens in the $2^{\text {nd }}$ appointment. Because at first, the impressions are taken. Both clinic and laboratory steps need sensitive working. After bracket placement, excessive adhesive must be cleaned before light curing. Also, there must be no air voids between bracket base and tooth. The indirect bonding onto short clinical crowns and extremely rotated teeth are difficult. ${ }^{[4,16-18]}$

\section{INDIRECT BONDING STEPS}

There are many kinds of indirect bonding, and new techniques were presented to literature recently. Most of these are the modifications of Thomas' indirect bonding technique. There are so many steps and applications in indirect bonding. Therefore, all these are opened to modification. The differences between all kinds of indirect bondings are basically related with adhesives used for bonding onto working models, transfer trays, and adhesives used for bonding to enamel. ${ }^{[15,17]}$ Expression below is from the original custom base indirect bonding technique. ${ }^{[19]}$

\section{Laboratory steps}

1. After taking accurate impression, fabricating the construction of an accurate working model and trimming working models ideally, the models should be dried thoroughly, the reference lines where the brackets will be placed optimal should be marked. Then resin separator should be applied 2 or 3 times with a 50:50 ratio of water to separating agent.

2. Brackets should be placed with resins, which were advised by the preferred indirect bonding technique onto working models (for example, "Original Custom Base Technique" uses chemically-cured resins such as Dyna-Bond). The excessive resins near the brackets should be taken carefully. When all the brackets are bonded, it is advised to wait for 10 minutes for curing.

3. The transfer trays, which take shapes thermally, are prepared for transferring the brackets to teeth. Soaking the models with trays in water for 20-30 minutes will allow for the release of the tray from the model.

4. The rough and irregular sides of the transfer trays should be trimmed and corrected. Bracket bases can be micro etched with aluminum oxide particles.

\section{Clinical steps}

1. The transfer tray and teeth should be clean and dry before bonding. If necessary, teeth should be polished with a periodontal paste.

2. Etching gel should be applied carefully; then, suctioned off the teeth, rinsed with water. The teeth should be air dried to ensure complete desiccation.

3. The resins should be applied to bracket bases and/ or teeth as instructed by the preferred indirect bonding technique (for example, "Original Custom Base Technique" uses universal resin for enamel and catalysor resin for bracket bases).

4. The transfer trays should be placed with finger pressure to ensure full contact between teeth and brackets. The bonding should be performed by appropriate curing type (chemically or lightly).

5. After bonding, the transfer trays should be removed with fingers and scaler. Excessive resins can be removed with scaler or tungten-carbide burr. The contact surfaces of the teeth should be checked with a dental floss. At last, the initial archwires should be inserted after bracket positions were checked.

\section{ACTUAL AND DIFFERENT INDIRECT BONDING TECHNIQUES}

\section{The sondhi method}

In this technique, the researchers made an effort to develop a resin designed for indirect bonding. Following laboratory tests and clinical trials, an effective indirect bonding procedure has been developed. The viscosity of the new resins was increased, so, it had an ability of filling any voids. They used resin A for the tooth surface and resin $\mathrm{B}$ for the bracket base.

For the transfer trays, they used two different layer; one inside (BioplastÔ) is softer than the outer one (Biocryl ${ }^{\mathrm{TM}}$ ). The outer one provides rigidity to the tray. ${ }^{[15]}$

\section{The vashi method}

In this technique, the researchers modified the transfer trays. They used a combination of thermoplastic glue and impression compound to prepare transfer trays. The impression compound is thermoplastic material used in prosthodontics. Glue consists of ethylene-vinyl acetate copolymer, which is non-toxic, non-cariogenic, and FDA-approved.

To prepare a transfer tray, impression compound is warmed with a flame torch and placed onto the occlusal 
and lingual surfaces of the teeth of the working models. After that, the brackets are placed onto the working models. Then, the glue is flowed from glue gun, adheres to the impression compound, and covers the brackets on all sides. ${ }^{[20]}$

\section{Indirect bonding with a thermal cured composite}

The use of thermally cured composite material has the advantage of creating unlimited working time. Therefore, bracket placement can be performed in stress-free environment and promotes more accurate and precise positioning of brackets.

The working models with the brackets are placed in toaster oven for curing at $325^{\circ} \mathrm{F}$ for 15 minutes. For the transfer trays, the polyvinyl siloxane impression material is applied over the thermally cured brackets. Then, vacuum-form thermoplastic material is used over the cast (working model), brackets, and impression material complex. ${ }^{[21]}$

\section{A technique for precision and efficiency by Guenthner and Larson}

The researchers offer two type of composites for bonding brackets onto the working models; thermally cured adhesive or APC (adhesive pre-coated) system. Also, there is a different transfer tray fabrication in this technique. They uses two part vinypolysiloxane putty material that is mixed with fingers. When the material is mixed, it is quite fluid and can easily flow and capture the undercuts of the brackets. This holds the brackets securely in the trays. The tray should be about $5 \mathrm{~mm}$ thick. This thickness provides enough support and rigidity. The trays are separated into segments for the 4 quadrant of the jaws and trimmed away from each other in the midline. ${ }^{[7]}$

\section{Prescription-based precision full arch indirect bonding}

In this technique, the researchers care firstly about vertical and horizontal lines on the working models. They offer the smallest diameter pencils for drawing lines. They draw vertical long axis lines on the models; these lines indicate the long axes of the teeth. Next, they draw horizontal lines on both models on the molars and bicuspids connecting the mesial and distal marginal ridges. They use a bow divider, measure $2 \mathrm{~mm}$ between the tips of the divider, and then transfer this measurement to the models by making a mark on the vertical lines (But on the second molars, they decrease this measurement by $0.5 \mathrm{~mm}$ ). By using this mark to place a second line parallel to the marginal ridge line, they determine the slot line. This slot lines will align the marginal ridges of the posterior teeth and place the cusp tips on a level plane. The $2 \mathrm{~mm}$ slot line is arbitrary, so a clinician can choose $2.5 \mathrm{~mm}$ for larger teeth if suitable. Till now, they finished all lines of the posterior teeth. By measuring the distance from the cusp tip on the first bicuspid to the slot line (it is usually $4.5 \mathrm{~mm}$ ), they find the upper central incisors slot lines. They decrease the measurement by $0.5 \mathrm{~mm}$ for the lateral incisors increase the measurement by $0.5 \mathrm{~mm}$ (same as central incisors) for the upper canines again. For the posterior part of the lower arch, the same methods are used including long axis lines, marginal ridge lines, and slot lines. The measurement for the distance from the cusp tip on the first bicuspid to the slot line is obtained and is transferred to the mandibular central and laterals. For the lower canines, this measurement is increased by $0.5 \mathrm{~mm}$. At the end, by placing these lines on the working models, a truly customized prescription is created.

For the composites, a two-part dual cure resin can be mixed and placed on the bracket base. A light-cured adhesive can also be used. For the fabrication of transfer trays, they use polyvinyl silioxane material. For the bonding on the teeth, they use Sondhi Rapid Set ${ }^{\circledR}(3 M$ Unitek) or Custom IQ ${ }^{\circledR}$ (Reliance Orthodontics, Itasca, IL). ${ }^{[22,23]}$

\section{Indirect bonding in lingual orthodontics}

In lingual orthodontics, the indirect bonding is preferred because;

- The variations on the lingual tooth structures complicate to fabricate a standard and suitable bracket

- To obtain an ideal view for bonding is very compelling

- If there is a mistake on bracket positions, it is also difficult to bend the arch wire for correction.

- The clinicians are not familiar to the lingual tooth morphologies. ${ }^{[2]}$

There are several indirect bonding techniques for lingual orthodontics. With the newly designed Orapix ${ }^{\circledR}$ (Orapix, Seoul, Korea) system; the 3D construction are established in computers and this system can make very sensitive bracket positioning on the transfer trays. ${ }^{[24]}$ In Incognito ${ }^{\circledR}$ (TOP Service, Bad Essen, Germany) System, the working models are created on the computers, the brackets and wires are designed, customized, and fabricated in CADCAM programs. Therefore, the bond failure risks are decreased, the artistic finishings can easily be done, and the adaptation of patient gets better, especially when speaking. ${ }^{[25]}$

\section{CONCLUSION}

Recently, technology became a part of everyday life. There are many developments in every branch of science. The orthodontists should be ready for developments in indirect bonding. High technology computer-driven systems were developed for orthodontics, especially for indirect bonding. One of these systems, SureSmile ${ }^{\circledR}$ system (Orametrix Inc., Richardson, TX), is based on intra-oral scanner that captures in vivo images of the dentition. The 3D digital diagnostic setups are obtained. Therefore, bracket positions are established, archwire geometry is configured, and custom indirect bonding transfer trays are constructed. ${ }^{[26,27]}$ In another system, 
OrthoCAD ${ }^{\circledR}$ (Cadent Inc., Carlstadt, NJ), plaster models are used to create digital models. By this way, the similar applications can be performed as in SureSmile ${ }^{\circledR}$ system. ${ }^{[28,29]}$

In a meeting about indirect bonding, the researchers were questioned about indirect bonding. Thomas stated that indirect bonding takes less clinical time (chair time) and is more accurate, he also reported 98\% success rate. In the same discussion, Zachrisson confirmed that it is better to position brackets on models. ${ }^{[30]}$

With any new development, there will be some trepidation. There is a natural fear of unknown. In indirect bonding, there were doubts about bond failures. However, 25 years of relaxed results have showed that it is suitable to pass to indirect bonding. ${ }^{[7]}$

\section{REFERENCES}

1. Kalange JT. Indirect bonding: a comprehensive review of the advantages. World J Orthod 2004;5:301-7.

2. Silverman E, Cohen M. A report on a major improvement in the indirect bonding technique. J Clin Orthod 1975;9:270-6.

3. Gottlieb, cohen M, Silverman E. JCO-interviews Morton Cohen and Elliott Silverman on indirect bonded practice. J Clin Orthod 1974;8:384-91.

4. Kasrovi PM, Timmins S, Shen A. A new approach to indirect bonding using light-cure composites. Am J Orthod Dentofacial Orthop 1997;111:652-6.

5. Hamula W. Direct bonding with light-cured adhesives. J Clin Orthod 1991;25:437-8.

6. Miles PG. Indirect bonding with a flowable light-cured adhesive. J Clin Orthod 2002;36:646-7.

7. Guenthner AT, Brent EL. Indirect bonding, a technique for precision and efficiency. Semin Orthod 2007;13:58-63.

8. Kalange JT. Ideal appliance placement with APC brackets and indirect bonding. J Clin Orthod 1999;33:516-26.

9. Hodge TM, Dhopatkar AA, Rock WP, Spary DJ. The Burton approach to indirect bonding. J Orthod 2001;28:267-70.

10. Koo BC, Chung CH, Vanarsdall RL. Comparison of the accuracy of bracket placement between direct and indirect bonding techniques. Am J Orthod Dentofacial Orthop 1999;116:346-51.

11. Roth RH. Functional occlusion for the Orthodontist. Part III. J Clin Orthod 1981;15:174-9.

12. Bennett JC, McLaughlin RP. Orthodontic management of the dentition with the preadjusted appliance. Oxford: Oxford Isıs Medical; 1998. p. 37.

13. Proffit WR. Contemporary Orthodontics. St. Louis: Mosby; 1986. p. 399-454.

14. Hocevar RA, Vincent HF. Indirect versus direct bonding: Bond strength and failure location. Am J Orthod Dentofacial Orthop 1988;94:367-71.

15. Sondhi A. Effective and effeicient indirect bonding: The Sondhi method. Semin Orthod 2007;13:43-57.

16. White LW. A new and improved indirect bonding technique. J Clin Orthod 1999;33:17-23.

17. Zachrisson BU, Buyukyilmaz T. Bonding in orthodontics, Orthodontics: Current principles and techniques. $4^{\text {th }}$ ed. Chapter 14. Graber-Vanarsdall 2005;1:579-659.

18. Scholz RP. Indirect bonding revisited. J Clin Orthod 1983;17:529-36.

19. Thomas RG. Indirect bonding: Simplicity in action. J Clin Orthod 1979;13:93-106

20. Vashi N, Vashi B. An improved indirect bonding tray and technique. J Indian Orthod Soc 2008;42:19-23.

21. Moskowitz EM. Indirect bonding with a thermal cured composite. Semin Orthod 2007;13:58-63.

22. Scholz RP, Swartz ML. Lingual orthodontics: A status report. Part 3. Indirect bonding - laboratory and clinical procedures. $\mathrm{J}$ Clin Orthod $1982 ; 16: 812-20$

23. Kalange JT. Prescription based precision full arch indirect bonding. Semin Orthod 2007;13:19-42.

24. Frost KB, Fillion D. An overall view of the different laboratory procedures used in conjuction with lingual orthodontics. Semin Orthod 2006;12:203-10.

25. Mujagic M, Fauquet C, Galletti C, Palot C, Wiechmann D, Mah J. Digital design and manufacturing of the Lingualcare bracket system. J Clin Orthod 2005;39:375-82

26. Sachdeva RC. SureSmile technology in a patient--centered orthodontic practice. J Clin Orthod 2001;35:245-53.

27. Sachdeva R, Fruge JF, Fruge AM, Ingraham R, Petty WD, Bielik KL, et al. Sure Smile: A report of clinical findings. J Clin Orthod 2005;39:297-314.

28. Redmond WR. Digital models: A new diagnostic tool. J Clin Orthod 2001;35:386-7.

29. Redmond WJ, Redmond MJ, Redmond WR. The OrthoCAD bracket placement solution. Am J Orthod Dentofacial Orthop 2004; 125:645-6.

30. Gorelick L, Masunaga GM, Thomas RG, Zachrisson BU. Round table: bonding. Part 3. J Clin Orthod 1978;12:825-37.

How to cite this article: Aksakalli S, Demir A. Indirect bonding: A literature review. Eur J Gen Dent 2012;1:6-9.

Source of Support: Nil, Conflict of Interest: None declared. 